\title{
CENSURA Y (RE)ESCRITURA EN EL TEATRO DE CARLOS MUNIZ
}

\author{
Diego Santos \\ Universidad Autónoma de Barcelona \\ dsantos@post.harvard.edu
}

RESUMEN / ABSTRACT

El artículo estudia la relación entre censura y (re)escritura en la dramaturgia de Carlos Muñiz. A través del estudio de dos de sus principales obras y de los expedientes censores de éstas, se analiza la deriva estética del autor en dos procesos de (re)escritura. Ambos constituyen una reacción del autor ante la censura y buscan generar lenguajes más susceptibles de escapar a ella. En el primero se produce el tránsito de lenguajes positivistas a otros más netamente expresionistas; en el segundo se observa cómo el expresionismo del autor se vio potenciado. Finalmente se hace una valoración general del impacto estético de la censura en la obra de Muñiz.

PALABRAS CLAVE: censura, reescritura, realismo, expresionismo, abstracto.

This article explores the relationship between censorship and (re)writing in Carlos Muñz' theatre. The study of two of his masterpieces and their censorial reports leads to the analysis of the author's (re)writing process as an aesthetic shift to escape from censorship. This process is explored in two instances: firstly from positivism to expressionism and secondly as an enhancement of the latter. Finally the aesthetic impact of censorship in Muñiz' theatre is assessed.

KEY WORDS: censorship, rewriting, realism, expressionism, abstract. 


\section{LA CENSURA TEATRAL DURANTE EL FRANQUISMO Y LA GENERACIÓN REALISTA}

Tras la victoria de los rebeldes nacionales, el régimen establecido por el general Franco en España tardó poco tiempo en generar una legislación específica que amparase el ejercicio de la censura teatral (Muñoz Cáliz 36). Este protocolo, que estaría vigente hasta 1978, años después de la muerte del dictador, determinó que los libretos de las obras de teatro pasasen por una serie de censores que habrían de informar sobre su oportunidad y adecuación, proponiendo en caso necesario cambios, supresiones e incluso prohibiciones tanto en el texto como en la puesta en escena. El sistema se articuló en torno a la defensa y la legitimación ideológica del régimen franquista, así como a un fuerte nacionalismo y una férrea moral católica. La censura, por tanto, basó su ámbito de actuación en los ámbitos sexual, político, del lenguaje y de la religión (Abellán 88-89). Dicha situación trajo consigo consecuencias dramáticas para la vida teatral española: el exilio o el silencio fueron las únicas opciones para los discursos que quedasen fuera de los estrechos márgenes de la ortodoxia franquista.

El panorama teatral de la España franquista de los años cuarenta distó mucho de gozar de una buena salud. Con el final de la Guerra Civil moría la gran tradición teatral republicana: voces como las de Lorca o Valle-Inclán se apagaron; otras, como las de Alberti o Max Aub, se exiliaron; y las de los autores que se quedaron en España se silenciaron o, lo que es peor, se autosilenciaron. La censura sometió a un severo escrutinio todas las obras y juzgó con especial severidad todo lo extranjero y "moderno", que comportaba siempre reminiscencias de la Segunda República y se entendía, por tanto, como símbolo de decadencia y barbarie. El hueco que dejaban todas estas ausencias se intentó llenar con dramaturgias como las de Felipe Lluch, que loasen a Franco y volviesen los ojos a la historia de la España eterna e imperial. Sin embargo, los gustos del público determinaron una vuelta a moldes teatrales conocidos, a un teatro más banal que evitase la confrontación entre vencedores y vencidos de la Guerra Civil y facilitase la evasión en un país económica y moralmente devastado. La comedia intrascendental, ligera, burguesa y meramente comercial acabaría poblando los escenarios de la década de los cuarenta. De este modo se perpetuaba un molde bien forjado en las décadas anteriores y se cerraba la puerta a toda innovación técnica, estética y formal. José María Pemán o Jacinto Benavente, nombres ya consolidados antes del conflicto civil, continuaron copando los grandes escenarios de aquellos primeros años de la dictadura. 
Si bien hasta entonces ninguna voz se atrevió a desafiar las reglas impuestas por el nuevo régimen, esta situación cambió en la década de los cincuenta. El estreno en 1949 de la obra de Antonio Buero Vallejo Historia de una escalera supondría un punto de inflexión en esta escena conservadora de los años cuarenta y marcaría el inicio de una nueva etapa del teatro español del siglo XX. La obra, historia de las frustraciones y penurias económicas de las familias de una misma escalera, contrastaba con el mundo amable de las comedias de evasión y abría la puerta a una realidad dura, reflejo de la angustiante situación económica que atravesaba la mayoría de los españoles de la época. Siguiendo la estela de Buero Vallejo, otros autores como Sastre, Olmo, Martín Recuerda, Rodríguez Méndez o Muñiz dieron luz a un teatro nuevo, de corte realista, que formulaba la denuncia de la situación creada por el franquismo mediante un fuerte grado de compromiso. Este neorrealismo ha sido interpretado por parte de la crítica como la recreación de una tragedia contemporánea que, si bien entronca directamente con los lenguajes positivistas del realismo, cuenta también con una capa simbolista que le concede un significado más trascendente; su realismo es, además, más ético y social que meramente costumbrista (Serrano 2788-90). Como no podía haber sido de otra manera, esta generación fue seguramente la más castigada por una inquebrantable censura presta a ver el peligro tras cada réplica, que apreció en estos textos una clara amenaza al statu quo del régimen.

En palabras del propio Muñiz, la censura jugó un papel capital a la hora de marginarle a él y a sus compañeros dramaturgos: "[la censura] ha hecho cuanto ha estado en sus manos -y en sus manos ha tenido toda la fuerza de la represión- para impedir que las obras que hemos logrado estrenar conservaran todo su vigor" (O’Connor y Pasquariello 15). Existen estudios (Muñoz Cáliz) que abordan de manera detallada y sistemática las vicisitudes a que fueron sometidas las obras de buena parte de estos autores críticos con el régimen: las prohibiciones y los cortes determinaron estrategias que ayudasen a la escritura dramática a sortear la barrera censora. Sin embargo, el trabajo de la crítica pasa por alto en buena medida la dramaturgia de Carlos Muñiz ${ }^{1}$, uno

\footnotetext{
Carlos Muñiz (Madrid, 1927-1994), dramaturgo español de la llamada “Generación Realista", liderada por Antonio Buero Vallejo y en la que se incluyen nombres como los de Lauro Olmo, Alfonso Sastre o José María Rodríguez Méndez. Su producción dramática arranca en 1955, con la obra Telarañas, y fue merecedora de galardones como el Premio Nacional de Cámara y Ensayo. Nunca se sintió cómodo con la etiqueta "realista", que transgredió en buena parte de sus obras. Fue funcionario del Ministerio de Hacienda, guionista en varias
} 
de los autores de este grupo más castigados por la censura. Otros nombres de esta generación, como Buero, Olmo o Rodríguez Méndez, desempeñaron un papel más central en la vida teatral de aquellos años y han relegado a un segundo plano más discreto la labor dramática de Muñiz. A ello se suma el hecho de que, además de dramaturgo, Muñiz se acabase convirtiendo en un hombre de televisión, lo que le restaría importancia en las tablas de la época; el dramaturgo Jesús Campos, por ejemplo, confiesa que en aquellos años Muñiz le era un desconocido porque había sido "avanzadilla de la emigración" hacia la televisión (en Muñiz, Teatro 5).

Aunque ha sido tradicionalmente englobado en la nómina de autores de la generación realista, el propio Muñiz parece no sentirse muy conforme con esta etiqueta, demasiado vaga, que se aplica a quienes adoptaron una actitud abiertamente crítica con la realidad socio-política del momento y con independencia de las preferencias estéticas de cada autor (O'Connor y Pasquariello 15). De hecho, la crítica ha venido señalando tres etapas bien diferenciadas en su creación dramática: una inicial realista, otra expresionista y una tercera y última basada en obras de corte histórico (Serrano). En este trabajo se ofrece un estudio del tránsito entre las dos primeras etapas y la mediación en él de la censura. Para ello, se analizarán los expedientes censores de dos obras, una de cada periodo, que recrean una narración similar. A través de dicho análisis se valorará cómo estas obras y sus lenguajes fueron entendidos, juzgados y condenados por el aparato censor del franquismo, así como el grado en que dicho aparato determinó la escritura del autor y su deriva estética.

\section{EL REALISMO DE MUÑIZ}

El primer estreno teatral de Muñiz, Telarañas, en 1955, le valió el aplauso del público, el mecenazgo de Buero y el optimismo de la crítica ante su futuro como autor, aunque el texto cosechó malas críticas (Serrano 2806). En la obra afloraba ya el compromiso de Muñiz con el hombre alienado por el sistema y la situación sociopolítica del momento, que se observará en las obras que comentaremos más abajo. A nivel estético, el crítico de Pueblo

novelas históricas y biográficas, y realizador del espacio dramático Estudio 1, de Televisión Española. 
señaló una oscilación "entre realismo y evasión" (Torres Nebrera, Carlos Muñiz 23-24), que se traducía como "la coexistencia pacífica" de naturalismo y expresionismo (Torres Nebrera, De Jardiel 284) en la obra. Esta dualidad estética del autor, inserto entre los lenguajes positivistas y la más abstracta vanguardia, abre la doble vía que analizaremos en este artículo. Las duras críticas al texto determinaron que Muñiz se volcase a partir de este momento a la confección de un teatro de corte más realista que demostrase a los críticos su capacidad dramatúrgica, ya que estos parecían desdeñar su aspecto más innovador. El propio autor manifestó que su llegada al expresionismo habría sido más temprana si la crítica no le "hubiera machacado prácticamente cuando estren[ó] Telarañas" (Muñiz, Tintero 26).

La auto-impuesta deriva hacia el realismo lleva al autor a la redacción de El grillo ese mismo año 1955. La obra mereció el Premio del Teatro Nacional de Cámara y Ensayo y, tras someterse a censura en 1956, el texto llegó a las tablas del Teatro Nacional María Guerrero en 1957. Mariano, su protagonista, es un hombre mediocre, un personaje abrumado por presiones económicas y diana de los engaños de todos, que se comporta como un grillo: "A los grillos nadie les hace caso y, sin embargo, fíjate cómo se les oye en el silencio del campo..., pero nadie les hace caso" (Muñiz, El grillo 141). Continuamente se lamenta por su precaria situación económica, que contrasta con la opulencia en que vive su hermano. Pretende que la vida de sus hijos sea mejor que la suya, pero ellos acaban reproduciendo el patrón y Pilar, la hija, lamenta que "Ni José Luis [hermano] ni yo ni nadie de esta casa tendremos nunca dinero" (139). Finalmente la familia accede al dinero del hermano del protagonista, a pesar de que este ha intentado abusar de la hija de Mariano. Este "concierto estridente", tal y como lo subtitula su autor, era la obra de corte realista que lo redimía ante la crítica y demostraba que podía llegar donde los críticos habían previsto.

Al mismo tiempo, el autor daba forma a los presupuestos del realismo inaugurado por Buero, en que "frente a la comedia amable, intrascendente y evasiva [...] lejos de concebir el arte como mera distracción, [el teatro se va a emplear] como vehículo de denuncia, en un intento de dar testimonio de las realidades más sórdidas y de dar voz a los perdedores del sistema" (Muñoz Cáliz 62). En la denuncia de la precariedad del orden social que se aprecia en esta obra señalan los críticos el comienzo de la protesta social en Muñiz (Zeller 41). El hecho de que las obras de este tipo apareciesen revestidas de un nuevo lenguaje teatral, que auguraba un cambio de patrón en las empobrecidas tablas del franquismo, determinó que los censores recibieran inicialmente estas 
obras con buenos ojos. "No obstante, estos juicios favorables irán cambiando a lo largo del franquismo, a medida que los censores tomen conciencia de las posturas progresistas de estos dramaturgos" (Muñoz Cáliz 65). En 1956, años después del estreno de Historia de una escalera, los censores ya estaban acostumbrados a obras de este tipo. La crítica social contenida en El grillo, por tanto, no habría de pasarle inadvertida a la censura.

El hecho de haber ganado el Premio del Teatro Nacional de Cámara y Ensayo garantizaba el estreno de la obra en dicho teatro. Para ello, el texto debía ser sometido, según el protocolo vigente, al juicio previo de la censura; en este caso, y frente a lo que sucedía con las solicitudes ordinarias, un único censor juzgó la obra. Adolfo Carril retrató al protagonista de la obra como un "tipo social de mediocres ambiciones" 2 y calificó el tema de la obra de "amargo". Interesante es, sin duda, su análisis artístico y técnico del texto: "Teatralmente analizada tiene algunos fallos y quizá pueda faltarle altura de expresión de arquitectura teatral y de procedimiento". A pesar de todo, el censor consideró que la obra podía autorizarse en los minoritarios teatros de cámara. En efecto, en 1955 se promulgaba la ley que instauraba un nuevo régimen teatral alternativo al general (también denominado comercial); se trataba del régimen de los teatros de Cámara y Ensayo, que autorizaba en salas pequeñas y para funciones únicas obras delicadas que se consideraban inadecuadas para el gran público pero inofensivas para un reducido núcleo de intelectuales urbanos (BOE 1955). El régimen, mediante este nuevo resorte legal, contentaba a una minoría potencialmente crítica (tanto los nuevos autores como su público) al tiempo que evitaba que este nuevo teatro ejerciese ningún tipo de impacto en la gran masa de espectadores.

Se impusieron también algunas tachaduras que suprimían la condición de funcionario del protagonista. En efecto, la censura prohibía "todo lo que atente de alguna manera contra nuestras instituciones" (BOE 1963, 3930) ${ }^{3}$, entre ellas la administración, que debía por tanto ser siempre presentada de manera inmaculada. En la obra, el ambiente laboral alienante y deshumanizador a que se sometía al personaje ponía en una situación delicada a la administración, por lo que simples referencias como "funcionario", "Ministerio" o "negociado"

2 Para las citas de los expedientes no se facilitará la referencia completa, ya que no son fuentes paginadas. Se trata de los expedientes de El grillo $(5 / 57)$ y El tintero $(306 / 60)$, Archivo General de la Administración, Alcalá de Henares, Madrid.

Hasta 1963 la censura carecía de normas explícitas, por lo que se citan las normas promulgadas aquel año. 
fueron eliminadas del texto, haciendo parecer que Mariano era un trabajador de una empresa, nunca un empleado público de un Estado de cuya defensa hizo bandera la censura. Tal y como nos ha llegado hasta hoy, el texto aún mantiene esa ambientación. La reescritura motivada por la censura no solo se aplicó, pues, en la representación, sino que se ha mantenido en la edición del texto ya en la época democrática. La censura, de este modo, ha de ser tenida en cuenta como agente activo en la génesis y fijación de los textos, como se estudiará más adelante.

El aparato teatral franquista permitía, de este modo, que la obra de Muñiz llegase a escena, desprovista de cualquier mención al estado franquista y su administración, aunque ésta hubiese sido del todo inocua desde el punto de vista político y moral. La obra, así, veía cambiado su enfoque conceptual y llegaba a las tablas en 1957 como función única de cámara. A finales de ese mismo 1957, el Instituto de Estudios Alicantinos hacía una nueva solicitud para montar la obra, también en régimen de cámara. El Delegado Provincial del Ministerio de Información y Turismo analizó el texto y, tras dictaminar que no atacaba a la moral, al dogma católico ni a las instituciones del Estado, lo autorizó para función de cámara, que para él era sinónimo de público "reducido y escogido". Aunque había sido premiada y autorizada, la obra se restringía a un público marginal ya que se intuía en ella una peligrosidad, no explícita pero sí latente, que inquietaba al régimen.

En 1959, la compañía de Andrés Mejuto solicitaba el montaje de la obra por diversas provincias en régimen comercial, lo que significaba un mayor impacto potencial en un público más amplio y exigía por tanto un análisis más exhaustivo del peligro que entrañaba el texto. Este hecho determinó una nueva lectura, esta vez por parte de dos censores, que debían dictaminar su idoneidad para este nuevo contexto. Ninguno alabó la calidad dramática de la obra: la consideraron aburrida e incluso juzgaron como torpe su diálogo. Lo más interesante, sin embargo, son los juicios que los censores hacían sobre su estética y su lenguaje teatral. Al tratarse de una comedia realista, la obra reflejaba "los hechos anodinos y vulgares de la clase media baja" de manera muy correcta y verídica, lo que uno de los censores veía como un aspecto positivo. El otro, sin embargo, parecía hacer una lectura más elaborada de este lenguaje artístico y de sus implicaciones: la obra, "resentida", desprendía un "tufillo revolucionario" y se insertaba en la "línea del teatro social que mira más al escenario, al ambiente que a la punzada argumental". Este censor veía una intencionalidad extra-escénica en el joven autor y alertó de las connotaciones que el lenguaje realista parecía acarrear. 
En efecto, una vez que la censura desentrañó su verdadera intención, las obras de corte realista fueron tachadas de marxistas por los censores, que las temieron sistemáticamente y las escrutinaron con meticulosidad. No podemos aventurar una hipótesis de hasta qué grado los censores, en su mayoría funcionarios ajenos a las letras, conocían, por ejemplo, los escritos de Lukács y su defensa del realismo como lenguaje de la revolución. En cualquier caso, sus recelos hacia este lenguaje teatral fueron constantes. El lenguaje realista conllevaba aspectos que incomodaban al régimen; al fin y al cabo se trataba de obras que "conta[ban] desde la escena los aspectos menos tolerables de una sociedad en la que los individuos más desfavorecidos por la fortuna lucha[ba]n por una vida sin horizontes" (Serrano 2789). Lo hacían, además, con presupuestos estéticos asequibles y planteando una homología clara entre escenario y realidad, es decir, una lectura interpretativa fácil susceptible de llegarle a un gran público. Al mismo tiempo, cualquier atisbo de crítica se hacía demasiado evidente para la tinta roja, que se cebó con este tipo de textos.

$\mathrm{Al}$ margen de los recelos propios hacia el realismo, los censores estaban alerta porque los peticionarios intentaban siempre burlar al sistema para obtener condiciones menos restrictivas. En este sentido, el texto que se presentó en la solicitud de 1959 debió de ser la versión original del autor, sin las supresiones que se habían impuesto en las solicitudes previas. De este modo, uno de los censores volvía a señalar la inviabilidad de que el personaje fuese un funcionario: "Aunque se llama funcionario del Estado, el protagonista, bien se vé [sic] que se trata de un empleado de oficina, pues toda su mentalidad y sus problemas surgen de su situación de oficinista de Empresa, ya que esos problemas serían distintos si el protagonista fuera funcionario del Estado”. Una vez más, la defensa del Estado se convertía en el caballo de batalla de los censores. Se impusieron, por tanto, tachaduras y modificaciones en la línea de lo que apuntaba el censor y siempre en defensa de la administración franquista: "Conviene sustituir la palabra funcionario por la palabra empleado, y la palabra despacho o ministerio por la palabra oficina, pues lo que sucede al protagonista, si fuera funcionario, no tendría razón de ser. Se vé [sic] que el autor no está fuerte en cuestiones de Derecho Administrativo". Estos ejemplos ilustran la continua negociación, en forma de tira y afloja, de los autores y peticionarios con la censura.

En 1962 hubo una nueva solicitud en Bilbao; en este caso la obra se autorizó sin cortes, precisamente porque el libreto enviado a censura no registraba ya los fragmentos con menciones directas del funcionariado 
que habían sido eliminadas en solicitudes previas. Constan dos solicitudes más, en 1967 y 1968, autorizadas en condiciones similares. De esta forma, el texto había sido finalmente autorizado por la censura y había llegado a un público amplio, pese a los temores iniciales que lo habían relegado al exclusivo circuito de teatros de cámara. Varios cortes en aspectos relativos a la administración pública alteraban su lectura pero, pese a la desconfianza que el lenguaje realista provocaba en la Junta de Censura, la obra acabó llegando a las tablas y al gran público.

\section{HACIA EL EXPRESIONISMO}

En 1958, el autor obtiene el premio Carlos Arniches por la obra El precio de los sueños, que cierra su etapa más realista, una vez que ya ha demostrado al establishment teatral que es capaz de hacer teatro de calidad. El vuelco estético se produce en 1960 con la obra La casa sin ventanas, cuyo título definitivo sería con el tiempo El tintero. Se trata de un texto abiertamente integrado en una estética expresionista que toma El grillo como "borrador" (Torres Nebrera, Carlos Muñiz 25) para sublimarlo. La prefiguración expresionista que se había visto en Telarañas cobra finalmente forma en esta obra, que supone un proceso de reescritura respecto a El grillo. La obra es una farsa expresionista en que Pérez, el protagonista, es un oficinista que apenas gana para subsistir en la ciudad y que vuelve cada fin de semana con su familia, al pueblo, tan agotado que tiene problemas para satisfacer sexualmente a su esposa: "Cada sábado sesenta kilómetros en bicicleta. Me compré la bici porque subieron el precio del coche de línea. Ya la he pagado, y monto en ella, pero me canso mucho! Y me da tos. Y cuando llego el sábado por la noche al pueblo, no tengo fuerzas para abrazar a mi mujer" (El tintero 14$)^{4}$. La mujer acaba siendo seducida por el maestro del pueblo y el protagonista se ve, por tanto, vejado en el ámbito personal. Esta vejación se traslada también al profesional, cuyas normas no entiende y donde se ve sistemáticamente atacado hasta perder el empleo: "Se ha excluido de ellas [de las nóminas], como usted sabe muy bien, a todos los que han llevado un comportamiento irregular y han fumado cigarrillos durante las hora de oficina, o han comido bocadillos, o han respirado hondo"

4 La imposibilidad de citar La casa sin ventanas, inédita, hace que las citas se hayan tomado de El tintero, reescritura de esta primera, como se indica más adelante. 
(21). En este entorno alienante el protagonista es recriminado por tener flores o escribir poesía y acaba siendo finalmente despedido. Asfixiado por una sociedad extremadamente deshumanizada y avasalladora, el protagonista se deja arrollar por un tren. Sin embargo, la crítica ha señalado que mientras Mariano, el protagonista de El grillo, es pasivo, Pérez se rige más por ideales y lucha de forma más activa (Cazorla 231).

La deriva estética de Muñiz es compleja. El lenguaje realista le había planteado al autor problemas con una censura recelosa de que los referentes fuesen fácilmente reconocibles por parte del público, especialmente si dichos referentes eran instituciones del régimen de Franco. El precio de los sueños, la segunda obra de Muñiz y premio Carlos Arniches, había seguido un itinerario estético similar, en su empeño por demostrarle a los críticos su capacidad de escribir buen teatro, es decir, un teatro de corte más realista. Hay quien ha señalado que existe en estas obras miedo a la censura al mostrar al antagonista de manera marginal (Zeller 42). En efecto, las estéticas positivistas, los realismos, ofrecían este problema en los regímenes totalitarios: la representación clara de la realidad planteaba una forma óptima de crítica accesible al gran público, pero también al censor.

Es más que factible, pues, que el autor abandonase esta línea estética, "porque entendía que por él no había posibilidad de llegar a ninguna meta apetecible" (Muñiz 23), lo que puede interpretarse como su deseo de burlar la censura. Con La vida sin ventanas el autor deja de lado la estética realista y se adentra en el terreno del expresionismo, lenguaje "impregnado de violencia reivindicativa" (Oliva y Torres Monreal 355) y cuya innovación técnica lo hacía susceptible de vehicular un mayor grado de protesta social que el "suave" naturalismo (Ríos Carratalá 120). En efecto, mientras que el realismo proporciona un fácil acceso a la literatura, los lenguajes de vanguardia determinan un acceso mucho más restringido a los textos; este mayor grado de abstracción del expresionismo presumiblemente dificultaría la lectura de los censores y posibilitaría una crítica más eficaz que la propuesta en $E l$ grillo, fuertemente mutilada. De esto modo la censura se mostraría a priori más benévola con las obras, acaso menos capaz de comprender su lenguaje teatral, menos asequible que el realista.

El lenguaje expresionista de La vida sin ventanas se deja notar en varios aspectos. La acotación inicial indica que "El decorado de esta obra ha de ser totalmente esquemático. Los elementos de decoración de cada uno de los cuadros estarán reducidos al mínimo" (9) y los personajes, por su parte, se definen también con muy pocos trazos: "La descripción que se hace de 
alguno de ellos a lo largo de la acción puede bastar para definirlos. Los demás no necesitan descripción" (9). Trazos que, además, inciden en descripciones deformantes: "[Frank] Es un tipo de hortera refinado. Traje verdoso, calcetines amarillos y zapatos colorados. Es algo cargado de hombros y lleva un lacio y repugnante bigote que cae hacia las comisuras de los labios con una languidez desesperante. Su palidez biliosa [...] le da un aspecto nauseabundo" (12); "[Livi] Es muy pálido. Casi amarillento" (19). La acción responde a estos personajes arquetípicos y es igualmente esquemática; la interpretación es, por tanto, lejana a la naturalista ${ }^{5}$. El protagonista se ve obligado a hacerse un bocadillo de papel, por no tener dinero para otra cosa y, en el segundo acto, aparece vestido como un presidiario.

La obra vehicula, a través de estos resortes, una denuncia social más generalizada que en sus obras anteriores. Monleón denomina esta nueva caracterización formal "estilización tragicómica" (Monleón 264). Si Mariano era un ser concreto, Pérez se convierte ahora en un símbolo (Llabrés 219); si la crítica de El grillo se hacía a nivel de un individuo determinado, en esta nueva obra se trasciende lo individual para dirigirse a la sociedad en general (Cazorla 230) y proponer una interpretación más trascendental. Esta nueva configuración de corte expresionista permitía una lectura en clave arquetípica y simbólica, por ende más general, al tiempo que determinaba que el texto fuese más complejo y, en el sentido que Carlson le confiere al término, que favoreciese la abstracción y el exceso sobre la mimesis (Carlson 346), imponiendo una lectura más difícil y una asimilación menos inmediata. A pesar de todo ello, la censura no se mostró más benévola de lo que lo había sido con El grillo.

A finales de 1960, la compañía comercial de Amparo Soler Leal ${ }^{6}$ presentó la obra a censura solicitando autorización para su montaje. El texto debió

5 El director del montaje de 1961 señala cómo los personajes son arquetipos y no deben someterse a una interpretación naturalista (Torres Nebrera, Carlos Muñiz 29).

Aunque la compañía que figura en la solicitud es la de Amparo Soler Leal, el nombre de De Quinto y del Grupo de Teatro Realista (GRT) de Alfonso Sastre aparecen en muchos de los documentos de esta serie. Se trata de la misma solicitud, realizada para el Teatro Recoletos de Madrid. La crítica siempre menciona que fue el GRT quien realizó el estreno; además, no se ha podido encontrar evidencia que hablase del estreno por parte de la empresa de Amparo Soler Leal, compañía comercial de gran trayectoria. Una hipótesis es que este grupo con solera amparase a la hora de llevar a cabo la solicitud a la joven compañía, seguramente más sospechosa ante la autoridad censora. 
de ser polémico desde su llegada a la Junta de Censura, ya que los tres informes que habitualmente se requerían se elevaron a cinco en esta ocasión. En ellos se incide en el pesimismo absoluto de la obra y se apuntan varios problemas desde el punto de vista moral. Por un lado está el tema siempre complejo del adulterio, que comete la mujer del protagonista. El supuesto suicidio de Pérez también se menciona entre los reparos, aunque el hecho de que aparezca barnizado de accidente casual parece solventar el problema. Sin embargo, más allá de los elementos concretos y puntuales que puedan transgredir las líneas rojas de la censura, el tono general de la obra es lo que más preocupa a la tinta censora. Su falta de expectativas, lo cerrado de su universo y el desamparo que rige la vida del protagonista incidían en valores que el régimen buscaba silenciar.

A pesar de todo, algunos censores vieron en el texto una tremenda exageración que el "espectador sensato" debería se capaz de valorar en su justa medida. Pero hubo voces en varias direcciones: algunas creyeron que la obra fomentaría en el público la caridad y la justicia, mientras que otras justificaron las desventuras que le sucedían al protagonista por su carácter apocado. Sin embargo, el juicio general fue que en la obra la moral social salía mucho más perjudicada que la individual, y el sentimiento generalizado de la censura puede resumirse en estas palabras de uno de los informantes: "aparte de ser falsa, [la obra] es demoledora y de perniciosas consecuencias. Fomenta la amargura y el resentimiento y muchos que llevan una vida estrecha podrían creer encontrarse en el mismo caso". La censura ejerce una vez más de garante de la integridad del público, al que quiere proteger de una obra claramente desalentadora y, en una lectura más profunda, contraria a la fe del catolicismo.

Más allá de la moral, hubo también voces que alertaron contra la problemática política de la obra. Es anecdótico que uno de los censores viese inconveniente que la mujer de Pérez cometiera adulterio con un maestro, funcionario público, y manifieste que el autor "ya podía haber echado mano de otro [personaje]". Como ya se señaló al tratar El grillo, la censura tenía por misión la defensa de las instituciones del Estado y no parecía adecuado que fuese un maestro el objeto de las burlas en el texto. Pero, como en el caso de las quejas de orden moral, la mayor parte de los comentarios de tipo político obviaban lo anecdótico y apuntaban a la obra en su conjunto, porque destilaba "tendencia" y "cierta demagogia de bachillerato". Algunos censores la entendieron como un ataque al egoísmo y la dictadura del dinero, mientras que uno de ellos ve en Pérez la "justificación de la violencia y el rencor marxistas", al estar el 
personaje sometido por la burguesía y el capitalismo. La virulencia de este informe culminaba con la sugerencia de prohibición por tratarse de un "panfleto lleno de violencia discursiva y pretensiones demagógicas". Es decir, a pesar de lo que podría haberse deducido del cambio de paradigma estético, la obra expresionista mereció un dictamen más severo que la realista gracias a una lectura cuidadosa que intentaba desentrañar los elementos "peligrosos", que se habían camuflado a través de un lenguaje de corte más abstracto.

En los informes existe una tercera línea crítica que se centra precisamente en la estética. Son comunes los comentarios sobre la falta de calidad de diálogos y trama, muchas veces reiterativos y guiados por la "motivación obsesiva, polémica y revolucionaria" que acaba de señalarse. Aunque el cambio de línea estética podría haberle hecho pensar al autor que la lectura revolucionaria del realismo marxista desaparecería, los censores siguieron alerta, listos para ver el peligro de alteración del orden social también en este lenguaje menos figurativo. Son además de un gran interés las interpretaciones que del nuevo lenguaje escénico hacen los censores. El término expresionismo no aparece en ninguno de sus informes, que, en su lugar, abundan en apreciaciones del tipo de "el lenguaje es ingenuo". Entienden que los personajes, especialmente Pérez, son símbolos más que encarnaciones realistas de personas concretas: "la acción toma estilo de 'ballet' en el que los personajes y su significación están estilizados, en rasgos extremosos e hirientes". A pesar de esta estilización, los censores consideran que el peligro no desaparece por la manipulación estilística y que los personajes siguen encerrando un potencial nocivo, pese a su naturaleza simbólica.

La deriva estética del autor, lejos de hacerle pasar desapercibido, había levantado la ira de una serie de censores no acostumbrados a lenguajes escénicos experimentales y recelosos de que se les intentase engañar a través de ellos. Sin embargo, lo más destacable respecto a la nueva configuración estética de la obra es la discordancia que se generó entre los censores. Aunque hubo quienes condenaron la obra, algunos censores optaron, sin embargo, por un juicio más benévolo, precisamente en virtud del lenguaje escénico abstracto, menos fácilmente asequible por parte del gran público. Constan comentarios sobre cómo el exceso de fantasía y la falta de verosimilitud (que es como los censores interpretan y conceptúan el alejamiento de la estética realista) le restan fatalismo a la obra y determinan que el público no la pueda tomar completamente en serio, haciéndola acaso válida para un público amplio. En esta línea permisiva se inserta uno de los comentarios que más llama la atención y que sugiere "castigar [subrayado del censor] al autor autorizandole 
[sic] esta comedia, y que se enfrente con el publico [sic], sin que la ominosa censura le convierta en un autor malogrado por falta de libertad intelectual para concebir obras de las calidades de esta historia-fantasia [sic]". Lo fantástico de la obra es interpretado como un atenuante, como un elemento que le quita peligro al texto y le concede un carácter más inocuo. En el comentario, el censor parece estar convencido de que el público no estaría preparado para enfrentarse a lenguajes escénicos tan innovadores, por lo que considera más apropiado para el autor el castigo de la taquilla que el de la tinta roja.

En general, la obra cosechó, como se desprende de los párrafos anteriores, una crítica por parte de la censura mucho más feroz y virulenta que El grillo. Sin embargo, los censores formularon en sus juicios asunciones de naturaleza opuesta: por un lado consideraron que el lenguaje, un tanto más abstracto, podía encerrar peligros, al igual que las obras realistas, y lo analizaron con mayor cautela y sospecha si cabe; por otro, concluyeron que quizá el público no podría desentrañar dichos peligros (como en buena parte tampoco ellos pudieron). La disparidad de estos comentarios desenmascara dos aspectos. El primero es que la censura no contaba con directrices estéticas. El segundo es el hecho de que el expresionismo se les planteó a los censores como una estética nueva para la que aún no disponían de herramientas apropiadas, que les desconcertó y les llevó a formular juicios contrarios en el seno de la Junta de Censura. En una situación como ésta, no autorizar la obra habría sido la solución más fácil; sin embargo, como se desprende de la cita del párrafo anterior, la censura parece ser ya consciente de las consecuencias de prohibir indiscriminadamente: en muchas ocasiones esta decisión contribuía a crear un halo de malditismo sobre autores jóvenes que podía, a la larga, llegar a generar en el gran público una fuerte demanda de esos textos. La ausencia de criterios ante la nueva estética, la imposibilidad de aprobar y la reticencia a prohibir debieron de generar un clima de desconcierto en la Junta de Censura que no se resolvió, con lo que, como en tantos otros casos, el expediente quedó en suspenso.

Aunque aún no se había producido el dictamen, la prohibición de La vida sin ventanas parecía inminente. Así se lo hizo saber el Director General de Cinematografía y Teatro al autor en una conversación telefónica de que queda constancia en el expediente. En ella el autor debió de escuchar las objeciones ofrecidas en los informes de los censores. Los "graves reparos de orden social" que encerraba el texto fueron el argumento blandido con mayor contundencia por el Director General ante un autor que, disconforme, le elevó una carta explicativa al día siguiente. En ella, Muñiz desgranaba su defensa contestando 
a los puntos que articulaban los informes de la Junta de Censura. El autor comienza en primer lugar hablando de "lo moral" y defiende que su opción no es otra que la de fustigar algunos defectos de su sociedad para conseguir en el público un "efecto purificador". Muñiz aborda también el capítulo de "lo social" negando categóricamente la existencia de cualquier efecto pernicioso de la obra. Su única intención, aclara, había sido la de despertar la conciencia del público, que es a priori acomodado y ajeno a situaciones de estrechez ${ }^{7}$ como las del personaje; con esta aclaración, Muñiz invalidaba las acusaciones de que la obra podría generar identificación con el personaje y, por tanto, angustia y descontento en buena parte del público. El autor argüía que su obra podía ser incómoda, pero bajo ningún concepto negativa o demoledora, y solicitaba por tanto su autorización para llevarla a las tablas.

El tratamiento que hace el autor de "lo estético" es sin duda la parte más interesante de la carta. Muñiz define su lenguaje escénico como "farsa expresionista", género basado en la "exageración de los tipos, de las situaciones, de todo el material dramático" hacia lo grotesco y caricaturesco. Precisamente desde la estética intentó el autor desmontar la supuesta interpretación marxista que la censura había hecho de su obra y de la que el Director General debió de informarle; sin ningún lugar a dudas, éste era el más peligroso de los argumentos censores y el que hacía pender la puesta en escena de un fino hilo. De este modo, Muñiz explicó a la luz de la naturaleza caricaturesca del lenguaje de la farsa expresionista el hecho de "que los ricos de mi obra sean más ricos, y los pobres, más pobres". Este elemento de la obra suponía una desviación estética con ánimo de caricatura y exageración, en el contexto del expresionismo. No cabía, por tanto, la lectura en clave realista, hecho que negaba cualquier viso de contenido social o político. Con una justificación estética, el autor dejaba a la censura sin argumentos. De este modo, Muñiz se desligaba de su trayectoria anterior, que la censura había vinculado a un realismo más marxista y beligerante, y aducía motivos únicamente estéticos para esta nueva configuración. Aunque en el fondo las intenciones extra-literarias del autor seguían intactas, Muñiz ofrece en su carta una teorización de los géneros teatrales con el fin de esquivar a la censura, intentando demostrar que su obra no tenía conexiones con la realidad y que a mayor abstracción, menor fuerza del mensaje.

7 Sin embargo, Muñiz manifestó en alguna ocasión que aspiraba a que su teatro gozase de aceptación entre los estudiantes y la gente más humilde (Monleón 263). 
La prohibición de obras teatrales ya en proceso de montaje y a menudo con pagos efectuados al teatro donde habrían de celebrarse conllevaba, como es natural, un enorme perjuicio económico que recaía sobre el empresario. Por esa razón y blandiendo ese argumento, apenas dos días después de la carta del autor, el director de la compañía le escribe también una carta al Director General. En ella incide en el proceso de producción de la obra y la problemática de suspenderlo; pero loa también "los valores literarios, dramáticos y morales" del texto y declara que una de las prioridades de la compañía es la de fomentar el teatro de los "nuevos autores españoles", presionando de manera más o menos sutil a la censura. Estas cartas no debieron de surtir efecto alguno, ya que, una semana después, el autor hubo de dirigirse nuevamente al Director General. En esta nueva ocasión lamenta Muñiz que, dos meses después de que se hubiese enviado la solicitud de autorización, no hubiera habido aún dictamen en ningún sentido. Pero, sobre todo, el autor expresa su preocupación ante la decisión de la empresa de sustituir su obra por otra ante la falta de autorización: "Por primera vez en mi lenta carrera de escritor, se me ofrece la posibilidad de estrenar en Teatro Comercial. Si no lo hago ahora, acaso tarde mucho en poder hacerlo. Personalmente, considero vital esta coyuntura que se me ofrece".

\section{UN NUEVO GIRO EXPRESIONISTA}

Motivada o no por estas cartas, lo cierto es que finalmente la censura reactivó el proceso de La vida sin ventanas, que se encontraba de facto en suspenso. Se le encargó un nuevo informe al censor Esteban y Romero, autor de las palabras que, semanas antes, habían sugerido la autorización como castigo para esta obra. No hay constancia explícita de que se le exigiese al autor una nueva versión con correcciones, pero el nuevo informe del censor valoraba un texto distinto del entregado en primera instancia. El lector evaluó esta nueva versión comentando los cambios y remitiéndose, para el resto de valoraciones, a su informe previo. No es descartable que se produjese una llamada telefónica de la que no queda registro en el expediente y que en ella se le sugiriese al autor una nueva redacción; práctica, por otra parte, nada ajena al proceder de la censura franquista. Sin embargo, Monleón (265) sugiere que esta nueva redacción no fue un requisito de la censura, sino que partió del propio autor. El crítico da cuenta de cómo Muñiz valoró que, mientras la oficina y los personajes se situasen en la sociedad española, la autorización 
seguiría quedando lejana. Este dato apunta a un proceso de reescritura que arranca del propio autor y que se activa como mecanismo para evitar la censura. Esta adecuación a las imposiciones del aparato censor son susceptibles, por tanto, de catalogarse como 'autocensura', ya que el autor decide reescribir su texto eliminando elementos 'incómodos' para la censura con el único fin de que fuese autorizado. Sin ser consciente, el autor colabora con el régimen y se convierte en un apéndice de su práctica del control cultural; pero, al mismo tiempo, esta autocensura le lleva a una indagación de orden estético que le permita una nueva expresión que, a su vez, burle a la propia censura. La censura, pues, motiva una reescritura que permita esquivarla.

Este ejercicio de reescritura es acaso lo más interesante de todo el expediente y supone una vuelta de tuerca más en el proceso de reescritura que se traza desde El grillo hasta El tintero. Si primero el autor había reformulado El grillo en una nueva versión (La casa sin ventanas) más acorde a sus gustos estéticos, en este último episodio del proceso La vida sin ventanas se convertiría en $E l$ tintero (inicialmente titulado La farsa del tintero). En este tránsito se establece una dialéctica entre el texto original, el censurado, y el que conocemos a día de hoy, el autorizado. Pérez, el protagonista, cambia en esta (re)escritura su identidad simbólica española por la de Crock, un abúlico ser sin afiliación nacional concreta, sin referente específico pero ajeno, en cualquier caso, a la España de Franco. Este proceso de abstracción lo sufrieron también el resto de personajes, que vieron sus nombres extranjerizados (Livi o Frank) o reducidos a genéricos de tipo "Conserje" o "Secretario"; en algunos casos se fue más allá y aparecieron otros nombres como "Pim" o "Pam". Mediante este recurso, Muñiz reduce los personajes, previamente caracterizados con apellidos españoles, a una "característica civil”" (Ryngaert y Sermon 66), lo que a su vez redunda en la abstracción y permite una interpretación menos local. Lo mismo sucede con la reducción de los apellidos españoles de los otros personajes a nombres como "Pim", que proponen una caracterización más burlesca y, en última instancia, expresionista. La ambientación también sufrió modificaciones en esta dirección: la palabra "funcionarios" se sustituyó, por ejemplo, por "empleados", cambiando así de manera clara los referentes de la obra y sacándola de un ministerio español para insertarla en cualquier empresa de otro mundo, real o inventado. Como el propio Muñiz ha señalado, de este modo se hacía inviable la identificación de la obra con la situación de España (en Primer Acto 5).

Si el paso de El grillo a La vida sin ventanas había estado ya marcado por una fuerte abstracción de corte expresionista, este nuevo proceso que 
acaba en El tintero supone una vuelta de tuerca más en la misma dirección. Los rasgos enumerados en el párrafo anterior le conceden a la obra un carácter más cercano a la farsa, una psicología más débil en los personajes, una mayor esquematización y una pérdida total de referentes, rasgos todos tradicionalmente asimilables a los lenguajes expresionistas. Lo cierto, sin embargo, es que estos rasgos, comúnmente destacados como exponentes del carácter expresionista de El tintero (Torres Nebrera, De Jardiel 293), no existían en primera instancia en La vida sin ventanas, sino que se incluyeron para ayudar a la obra a esquivar la barrera censora. Este proceso ilustra cómo, si bien Muñiz había declarado su anhelo por llegar al expresionismo, la censura determinó el lenguaje teatral de su obra y lo empujó hacia posiciones más claramente expresionistas que las concebidas en primera instancia.

En el expediente de censura existe un único Ejemplar de Archivo que muestra el proceso de (re)escritura y negociación con la autoridad censora. En algunas páginas el protagonista es aún Pérez, pero en otras ha habido cambios y es ya Crock. Hay marcas en menciones a ordenanzas y jefes de personal que debieron de estudiarse detenidamente y quizá negociarse en cada caso. También las hay en acotaciones que inciden en el carácter violento de los superiores de Pérez o en la imagen del protagonista. En una de ellas se indica que el atuendo de Pérez es similar al de un recluso, sugiriendo que el lugar de trabajo era una cárcel. Este aspecto debió de discutirse con la autoridad censora, ya que hay un comentario del autor al margen, en que se lee: "Si es preciso se quita, pero estimo que da un caracter [sic] más profundamente grotesco a la farsa". La negociación debió saldarse de parte de Muñiz, porque este atuendo consta en las ediciones que hoy tenemos de la obra. De la apariencia del volumen que consta en el expediente de censura, de la existencia en él de varias tintas, varios tipos de marcas, insertos y correcciones, se desprende que el texto se negoció con la censura de manera detenida y analizando los casos problemáticos uno a uno, por lo que es posible determinar que el proceso de reescritura, es decir, El tintero, provenga más de un acuerdo de las dos partes que de un ejercicio solitario del autor.

La nueva versión parecía, en cualquier caso, apta para la escena. En su valoración del nuevo texto, el censor celebraba los cambios, que habían "quitado mucha 'carga' politico-social [sic] a esta obra". Aunque Esteban y Romero consideró que los reparos de orden moral seguían intactos, concedió que el texto no revestía "especial peligrosidad" y abogó por su autorización en base a dos motivos: la poca "garra" de la trama y lo reducido y elitista del teatro donde había de representarse. La versión más descafeinada y la opción 
de los elitistas teatros de cámara le valían a El tintero su llegada a las tablas. Sin embargo, el censor impuso una única condición, que hemos visto ya en otros puntos del proceso: que el maestro con quien la mujer del protagonista cometía adulterio no fuese un empleado público. La obra, finalmente, se aprobó y el estreno se produjo en el Teatro Recoletos de Madrid ya en 1961.

El mismo año del estreno en Madrid, una compañía de cámara asturiana solicitó autorización para montar de nuevo la obra. En esa ocasión, dictaminado ya el texto, bastó el informe del Delegado Provincial. Pese a destacar su falta de ejemplaridad (la exaltación de la amargura, la desesperación, el suicidio y la caricatura amarga y sangrienta que la obra es de la propia vida), el censor señaló también sus momentos de comicidad y el valor de la amistad como atenuantes. La obra se autorizó para una única sesión de cámara, mientras se indicaba que el texto solo estaba autorizado para funciones comerciales en Madrid. Tres solicitudes posteriores de La Laguna, San Sebastián y Talavera de la Reina, de entre 1961 y 1964, fueron devueltas sin resolución por no ajustarse al texto autorizado, sino al publicado por la revista Primer Acto; la censura quería asegurarse de que se respetaba la versión autorizada, en que Pérez se convertía en un extranjero y el texto había pasado de localizarse en un ministerio a hacerlo en una empresa, negando toda coincidencia con la administración del régimen franquista. Ninguna de las tres compañías volvió a formular su petición; hubo sin embargo tres grupos amateur de Madrid (1968 y 1972) y Tolosa (1969) que sí se ciñeron a la versión autorizada y lograron permiso para la representación para mayores de 18 años.

\section{REESCRITURA Y CENSURA}

El grillo, un texto realista con carga social, una obra de fácil lectura y equiparación con la realidad, se había visto castrado por una censura ávida de imponer su criterio e intransigente con los ataques a la moral o las instituciones del régimen. Esta férrea censura debió de llevar a Muñiz a un replanteamiento estético que le permitiera esquivarla y dar salida a su teatro crítico. La semilla del expresionismo, que el autor había sembrado en su primera obra, germinó como alternativa abstracta con que disfrazar el mensaje. Muñiz planteó La casa sin ventanas como una reelaboración de $E l$ grillo desde una estética expresionista, proponiendo una homología con la realidad más oscurecida y haciendo un tratamiento más universal del mismo tema. Sin duda el autor pensó que este nuevo lenguaje le permitiría sortear 
la censura y llegar al público de manera más directa. Ésta es la primera fase del proceso de reescritura que culminaría con El tintero.

El resultado, como se ha mostrado, fue bien distinto y la obra se analizó con aún más desconfianza. El cambio de paradigma estético de La vida sin ventanas levantó sospechas en una censura no habituada a la experimentación formal y seguramente más cómoda con los lenguajes realistas que, aunque críticos, mostraban sus aspectos espinosos de manera más explícita, facilitando la labor de la tinta roja. En efecto, los censores se habían mostrado menos alerta con la primera obra, pese a su desconfianza hacia el realismo, acaso porque la habían entendido mejor y los cortes impuestos habían atajado el problema de manera clara. El salto a una estética de corte más vanguardista les había, de alguna manera, pillado por sorpresa. El carácter abstracto de la obra proponía una lectura en clave simbólica que hablaba de la falta de esperanza del hombre, no de un hombre, lo cual parecía incompatible con el dogma católico del que la censura había hecho bandera. Además, había referentes en clave española y la censura, fuertemente nacionalista, no podía permitir ningún tipo de ambigüedad al respecto.

Se hizo por tanto necesaria una nueva reescritura del mismo tema que forzara una lectura si cabe aún más abstracta para que el texto pudiese ser por fin autorizado y le llegase al público. La vida sin ventanas se había quedado en tierra de nadie: contaba tanto con elementos del realismo (nombres, localizaciones) como con otros expresionistas (universalidad, esquematización) que habían despertado las sospechas de la censura. Había que llevar el texto más allá y, entre otras medidas, los referentes concretos se desplazaron a nombres y lugares no solo de fuera de España, sino de fuera de toda coordenada espacial. Esta vuelta de tuerca parecía restarle peligrosidad a la obra y hacerla viable para la escena. Este tercer estadio del proceso de reescritura se había bautizado con el nombre de El tintero.

En este punto hay que enjuiciar en su justa medida la deriva de este proceso de (re)escritura. Es un hecho que la tendencia de Muñiz fue hacia el expresionismo, hacia lo abstracto, como se desprende de la transición entre El grillo y La vida sin ventanas. Sin embargo, muchos de los elementos que hacen de El tintero una obra más expresionista que La vida sin ventanas se deben a la existencia misma de la censura, como se ha demostrado en las páginas anteriores. Se llevase a cabo este proceso de (re)escritura en solitario o en intensa negociación con los censores, lo cierto es que fenómenos como los cambios de nombres de los personajes y la pérdida de referencias espaciales son consecuencia directa de la necesidad de burlar 
la tinta roja y llegar al escenario. El protagonista de El tintero sería Pérez en lugar de Crock y la ambientación sería un ministerio español en lugar de una anónima oficina de no haber sido por la existencia de la censura. Los cambios proporcionaron un fuerte barniz de abstracción a la obra, que agudizó su carácter expresionista con la existencia de personajes como Pim y Pam, que actuaban más como marionetas, como encarnaciones huecas, que como psicologías vivas. Aunque Pérez sea un nombre abstracto que funcione de manera óptima en una obra expresionista, Crock le añade un grado de indeterminación e inconcreción que ahonda en ese halo expresionista que reina en la obra, al tiempo que facilita el trámite censor. Lo mismo sucede con el resto de personajes: los Sabas y Povedilla de La casa sin ventanas no existen en El tintero, que se puebla ahora de nombres como Livi o Slamb, que apuntan en la misma dirección.

Por tanto, hay que aclarar algunas cuestiones de la lectura expresionista tradicionalmente hecha de El tintero. La obra atiende, en efecto, a esta lectura, pero puede concluirse que la censura ayudó en esta deriva estética a través de un proceso de (re)escritura que no siempre es evidente. Si bien la crítica ha observado en la evolución de El grillo a El tintero el deseo de Muñiz de llegar al expresionismo, el papel desempeñado por la censura en esta evolución no ha sido debidamente enjuiciado hasta el momento. El eslabón intermedio de La casa sin ventanas, del que no había constancia, es sin duda un paso necesario para llegar a El tintero. Sin la censura, El tintero que hoy conocemos se reduciría a su versión tamizada de La casa sin ventanas. Este hecho tiene también consecuencias en el ámbito de la edición: las ediciones del texto que a día de hoy existen son herederas de una hipotética primera versión que fijó estos cambios impuestos a la representación teatral. Por tanto, puede concluirse que El tintero nunca fue la idea primitiva del autor y que, sin embargo, La casa sin ventanas es un gran desconocido para el gran público, a pesar de ser la propuesta original de Muñiz. La censura, operando como autocensura, motivó un proceso de reescritura que, si bien es cierto que radicalizó el expresionismo al que el autor siempre había pretendido llegar, acabó plasmando una idea que no coincidía íntegramente con la que Muñiz había tenido en primera instancia. En este sentido es preciso evaluar el hecho de que buena parte de los textos teatrales que conocemos hoy en día responden a formas reescritas por los autores para evitar, o más bien para acomodarse, a la censura. Si bien la sustitución por los textos originales es una quimera, se hace necesario conocer estos textos previos para analizar en su justa medida la intención del autor y su forzado proceso de reescritura. 
Serrano (2807) manifiesta cómo "la pieza [El tintero] representa el kafkiano mundo de una oficina con sus seres idénticos y uniformados (Pim, Pam, Pum)", lo cual es cierto; ¿pero fue esta la intención original del autor? ¿O se vio empujado hacia este tipo de personajes por la censura? El argumento que se blande en este trabajo es que precisamente la censura determinó esta deriva estética, llevando al autor más lejos en sus presupuestos expresionistas de donde habría llegado si la representación teatral no hubiese estado sometida a la censura previa. Serrano señala también que la obra bebe del realismo esperpentizador, como si hubiese pasado a través del espejo valleinclanesco (2808); aunque estas afirmaciones no son incorrectas, hay que señalar a la censura como juez y parte en esta causa. Sin saberlo, los censores estaban llevando la creación por el camino de la vanguardia. De este modo, censura y (re)escritura van, tanto en este como en muchos otros casos, de la mano.

La investigación demuestra cómo el impacto del aparato censor no se limita únicamente a cortes y prohibiciones, sino que ejerce una influencia directa en la dramaturgia. Según el propio autor manifestaba, la censura le quitó fuerza a su obra y determinó un impacto devaluado en la audiencia; pero, además, la censura, o más bien el deseo por esquivarla, determinó que Muñiz se viese obligado a (re)escribir su teatro indagando nuevas formas, siguiendo líneas estéticas que le permitiesen cumplir sus propósitos. La experimentación formal a través de la reescritura es, pues, una más de las consecuencias del complejo fenómeno censor, que sin embargo suele enjuiciarse únicamente desde el prisma de las prohibiciones. Este trabajo no pretende en ningún caso señalar esta experimentación forzada como una virtud de la censura, ni tampoco concluir taxativamente que fue la censura quien condujo a Muñiz al expresionismo; bien al contrario, se ha citado el deseo del autor por llegar a esta estética una vez que se hubiese ganado un lugar en el establishment teatral. Lo que sí se concluye es que la censura determinó, en buena medida, la dramaturgia del autor al contribuir en (la acentuación de) su deriva expresionista. El tintero que hoy conocemos, en definitiva, no habría sido posible sin la existencia de la censura.

\section{BIBLIOGRAFÍA}

Abellán, Manuel L. Censura y creación literaria en España (1939-1976). Barcelona: Península, 1980.

Archivo General de la Administración. Expedientes censores de de El grillo (5/57) y El tintero $(306 / 60)$. 
Boletín Oficial del Estado. "Orden 25 mayo 1955, por la que se reglamentan y protegen las actividades de los Teatros de Cámara o Ensayo y Agrupaciones escénicas no profesionales". 15 de Julio de 1955: 4291-92.

"Orden de 9 de febrero de 1963 por la que se aprueban las 'Normas de censura cinematográfica"”. 8 de marzo de 1963: 3929-30.

Carlson, M. Theories of the Theatre. A Historical and Critical Survey, from the Greeks to the Present. Ithaca y Londres: Cornel University Press, 1993.

Cazorla, Hazel. “Simbolismo en el Teatro de Carlos Muñiz”. Hispania 48: 2 (1965): 230-33.

Llabrés, J. “Carlos Muñiz, un representante de la nueva generación.” Papeles de Son Armadans. 110 (1965): 217-228.

Lukács. G. "Realism in the Balance". Vincent B. Leitch (ed.). The Northon Anthology of Theory and Criticism. Nueva York y Londres: Norton \& Company, 2001. 1033-58.

Monleón, José. “El tintero español.” Carlos Muñiz. Teatro escogido. Madrid: Asociación de Autores de Teatro, 2005. 261-70.

Muñiz, Carlos. El tintero. Madrid: Alfil, 1967.

Teatro escogido. Madrid: Asociación de Autores de Teatro, 2005.

"El grillo". En Teatro escogido. Madrid: Asociación de Autores de Teatro, 2005. $115-188$.

[sin título]. Primer Acto 102 (1968): 23.

Muñoz Cáliz, Berta. El teatro crítico español durante el franquismo, visto por sus censores. Madrid: Fundación Universitaria Española, 2005.

O’Connor, Patricia y A.M. Pasquariello. "Entrevista con Carlos Muñiz.” Estreno 2: 2 (1976): 14-16.

Oliva, C. y Torres Monreal, F. Historia básica del arte escénico. Madrid: Cátedra, 2003.

Primer Acto, "Encuesta sobre la censura." Primer Acto 166 (1974): 4-11.

Ríos Carratalá, J.A. "Introducción [a El grillo].” Carlos Muñiz. Teatro escogido. Madrid: Asociación de Autores de Teatro, 2005. 117-121.

Ryngaert, Jean-Pierre y Julie Sermon, Le personnage théâtral contemporain: décomposition, recomposition. Monteuil-sous-Bois: Éditions Théâtrales, 2006.

Serrano, Virtudes. "Los autores neorrealistas". Javier Huerta Calvo (dir.). Historia del teatro español, vol. II. Madrid: Gredos, 2003. 2788-2819.

Torres Nebrera, Gregorio, De Jardiel a Muñiz: estudios sobre el teatro español de medio siglo. Madrid: Fundamentos, 1999.

"Carlos Muñiz: entre la rebeldía y la insatisfacción." Carlos Muñiz. Teatro escogido. Madrid: Asociación de Autores de Teatro, 2005. 9-38.

Zeller, L.L. "La Evolución Técnica y Temática en el Teatro de Carlos Muñiz.” Estreno 2: 2 (1976): 41-49. 